\title{
Risk Factors for Colorectal Cancer in Thailand
}

\author{
Kirati Poomphakwaen ${ }^{1}$, Supannee Promthet ${ }^{1 *}$, Krittika Suwanrungruang ${ }^{2}$, \\ Siriporn Kamsa-ard ${ }^{3}$, Surapon Wiangnon ${ }^{4}$
}

\begin{abstract}
Background: Colorectal cancer (CRC) is one of the most common cancers worldwide. This study aimed to investigate the risk factors for colorectal cancer in the Thai population. Materials and Methods: A cohort study was carried out in Khon Kaen, Thailand, including 71 cases of histologically confirmed CRC patients among 19,861 participants, aged 30-69 years, who were recruited for a cohort study during the period 1990-2001. Participants were followed-up until 31 December, 2013. To identify factors associated with the incidence of colorectal cancer, hazard ratios were evaluated using Cox proportional hazard regression. Results: No environmental variables could be shown to be significantly related to the risk of $\mathrm{CRC}$. Although in our sample, CRC was more prevalent among males, ex-smokers, and those who drank alcohol beverages $\geq 50$ gram/day, but we could not demonstrate significantly associations $($ HRmale $=1.67,95 \%$ CI, 0.80-3.49, HR ex-smokers $=1.34,95 \%$ CI, 0.52-3.46, and HRalc $\geq 50=1.08,95 \%$ CI, 0.43-2.71). Individuals within the sample with a family history of cancer, working hour $>8$ hours per day, and current-smokers appeared to have decrease risk of CRC, but again these relationship could not be shown to be significantly associated (HRfam cancer $=0.96,95 \%$ CI, 0.85-1.09, HRwork $>8=0.84$, 95\% CI, 0.36-1.93, and HRcurrent-smoker $=0.51,95 \%$ CI, 0.18-1.38). Conclusions: We found no evidence of environmental factors effecting the risk of CRC. There is a need for further research to determine why factors identified risk in other populations appear to not be associated with CRC risk in Thais.
\end{abstract}

Keywords: Colorectal cancer - risk factors - Thailand

Asian Pac J Cancer Prev, 16 (14), 6105-6109

\section{Introduction}

Globally, colorectal cancer (CRC) is the third most common form of cancer in males and the second most common cancer in females (Ferlay et al., 2013). Although CRC is stabilizing or decreasing in the most western developed countries, the incidence of $\mathrm{CRC}$ is rapidly increasing in Asia, in general, and in Thailand, in particular (Sung et al., 2005; Yee et al., 2009; Cho and Kim, 2011; Ferlay et al., 2013). The incidence of CRC in Thailand now ranks as the third most common cancer in males and fifth in females (Ferlay et al., 2013).

It is established that CRC is a complex disease, and its incidence is related to both genetic, and environmental factors, especially those associated with a Western lifestyle. Several studies have indicated dietary habit and alcohol intake, inactive lifestyle, smoking, obesity, family history of colorectal cancer, and especially diet with high fat, as possible risk factors for developing CRC (Wang et al., 2010; Durko and Malecka-Panas, 2014; De Stefani et al., 2012; Ganesh et al., 2009). However, the degree and significance of the various environmental risk factors varies widely across studies, and populations, this needs future investigate.
Previous colorectal cancer studies in Thailand reported that red meat (beef and/or pork), and alcohol consumption associated with colorectal cancer in the Thai population (Promthet et al., 2010; Promthet et al., 2012). Although several cohort studies of CRC have been conducted in other countries (Hsing et al., 1998), no CRC cohort study has ever been conducted in Thailand. The present prospective study aims to identify which environmental factors associated with CRC in the Thai population.

\section{Materials and Methods}

This was a prospective cohort study, in which data were obtained from the Khon Kaen Cohort Study (KKCS), Faculty of Medicine, Khon Kaen University, in Northeast Thailand. The KKCS was conducted from 1991 to 2001, and recruited participant aged 30 to 69 years, and living in the Khon Kaen Province. The cohort included 19,861 participants with data obtained by structured questionnaire. Based on the Khon Kaen provincial cancer registry, 71 cases were histologically confirmed CRC among the 13,489 female, and 6,372 male cohort members. Follow-up was completed for all participants. 
Table 1. Baseline Characteristics of Subjects

\begin{tabular}{|c|c|c|}
\hline Baseline charateristics & $\begin{array}{c}\text { Subjects } \\
(\mathrm{n}=19,861)\end{array}$ & percent \\
\hline \multicolumn{3}{|l|}{ Sex } \\
\hline Male & 6,372 & 32.1 \\
\hline Female & 13,489 & 67.9 \\
\hline \multicolumn{3}{|c|}{ Age at recruitment (Years) } \\
\hline$<40$ & 2,776 & 14.0 \\
\hline $41-50$ & 7,190 & 36.2 \\
\hline $51-60$ & 6,947 & 35.0 \\
\hline$>60$ & 2,948 & 14.8 \\
\hline Mean (S.D.) & $51(8.65)$ & \\
\hline \multicolumn{3}{|l|}{ Marital status } \\
\hline Single & 456 & 2.4 \\
\hline Married & 16,228 & 84.6 \\
\hline Separate, widow & 2,501 & 13.0 \\
\hline \multicolumn{3}{|l|}{ Education } \\
\hline Illiteracy & 515 & 2.7 \\
\hline Primary school & 17,958 & 92.8 \\
\hline Secondary or above & 876 & 4.5 \\
\hline \multicolumn{3}{|l|}{ Occupation } \\
\hline Agriculture & 14,324 & 84.3 \\
\hline Others & 1,484 & 8.7 \\
\hline Unemployed & 1,182 & 7.0 \\
\hline \multicolumn{3}{|c|}{ Working hours/day (hours) } \\
\hline Unemployed & 1,182 & 7.3 \\
\hline$<8$ & 4,163 & 25.6 \\
\hline 8 & 8,382 & 51.6 \\
\hline$>8$ & 2,513 & 15.5 \\
\hline \multicolumn{3}{|l|}{ BMI history $(\mathrm{kg} / \mathrm{m} 2)$} \\
\hline$<18.5$ & 6,169 & 39.4 \\
\hline $18.5-22.9$ & 1,051 & 6.7 \\
\hline $23-24.9$ & 2,982 & 19.1 \\
\hline $25-29.9$ & 4,418 & 28.2 \\
\hline $30+$ & 1,023 & 6.6 \\
\hline
\end{tabular}

Data collection

All participants of the KKCS were followed up until
December 31, 2013, and all data of the KKCS participants were linked to the Khon Kaen Population-based Cancer Registry by the RECLINK program to identify patients with a diagnosis of CRC. All CRC diagnoses were histologically confirmed, and the date of diagnosis was obtained from medical records.

Data for analyses were extracted from the KKCS database which, collected at baseline, included the demographic and environmental variables, sex, age at recruitment, marital status, education level, occupation, working hour per day, history of body mass index (BMI), family history of cancer, history of smoking, duration of smoking, number of cigarette per year, history of alcohol drinking, duration of alcohol drinking, frequency of drinking, and units of alcohol (grams/day). Person-times were computed from date of recruitment to KKCS, date of diagnosis, date of loss to follow-up or withdrawal, and date at the end of study.

\section{Statistical analysis}

Crude and adjusted estimates of associations between potential environmental risk factors and CRC were estimated using hazard ratios (HRs) with $95 \%$ confidence interval derived from Cox proportional hazard regression analysis. All analyses were conducted using STATA Version 10.0 (StataCorp., 2007), and a significance level of 0.05 was used throughout.

\section{Ethical approval}

The present study was approved by the Khon Kaen University Ethics Committee for Human Research (reference no. HE561328), and was adhered to the Declaration of Helsinki and the Good Clinical Practice Guidelines of the International Conference on Harmonisation.

Table 2. Univariate Analysis of Environmental and Demographic Factors

\begin{tabular}{|c|c|c|c|c|c|c|}
\hline Factors & Numbers & $\begin{array}{l}\text { Number } \\
\text { of CRC }\end{array}$ & $\begin{array}{c}\text { Person-time } \\
\text { (person-yesrs) }\end{array}$ & $\begin{array}{c}\mathrm{IR} / \\
100,000\end{array}$ & $\begin{array}{c}\mathrm{HR} \\
(95 \% \mathrm{CI})\end{array}$ & $\mathrm{p}$-value \\
\hline Sex & & & & & & 0.241 \\
\hline Female & 13,489 & 44 & 212,837 & 21 & 1 & \\
\hline Male & 6,372 & 27 & 97,774 & 27 & $1.34(0.83-2.16)$ & \\
\hline Age at recruitment (years) & & & & & & 0.0002 \\
\hline$<40$ & 2,776 & 6 & 51,624 & 11 & 1 & \\
\hline $41-50$ & 7,190 & 16 & 116,710 & 13 & $1.27(0.50-3.26)$ & \\
\hline $51-60$ & 6,947 & 32 & 102,554 & 31 & $3.03(1.26-7.29)$ & \\
\hline$>60$ & 2,948 & 17 & 39,722 & 42 & $4.29(1.68-10.98)$ & \\
\hline Marital status & & & & & & 0.148 \\
\hline Single & 456 & 1 & 7,378 & 13 & 1 & \\
\hline Married & 16,228 & 56 & 256,054 & 21 & $1.63(0.23-11.81)$ & \\
\hline Separate, widow & 2,501 & 14 & 36,612 & 38 & $2.94(0.39-22.37)$ & \\
\hline Education & & & & & & 0.530 \\
\hline Illiteracy/primary school & 18,473 & 65 & 289,961 & 22 & 1 & \\
\hline Secondary school/above & 876 & 2 & 13,659 & 14 & $0.66(0.16-2.68)$ & \\
\hline Occupation & & & & & & 0.394 \\
\hline Agriculture & 14,324 & 46 & 215,467 & 21 & 1 & \\
\hline Others & 1,484 & 6 & 23,122 & 25 & $1.20(0.51-2.81)$ & \\
\hline Unemployed & 1,182 & 8 & 20,213 & 39 & $1.74(0.81-3.70)$ & \\
\hline Working hours/day (hours) & & & & & & 0.438 \\
\hline 8 & 8,382 & 27 & 125,549 & 21 & 1 & \\
\hline$<8$ & 4,163 & 17 & 61,342 & 27 & $1.31(0.71-2.40)$ & \\
\hline$>8$ & 2,513 & 7 & 39,099 & 17 & $0.82(0.36-1.88)$ & \\
\hline Unemployed & 1,182 & 8 & 20,214 & 39 & $1.70(0.77-3.77)$ & \\
\hline
\end{tabular}


Table 2 (continued). Univariate Analysis of Environmental and Demographic Factors

\begin{tabular}{|c|c|c|c|c|c|c|}
\hline \multicolumn{6}{|l|}{ BMI history (kg/m2) } & \multirow[t]{6}{*}{0.544} \\
\hline $18.5-22.9$ & 1,051 & 4 & 15,568 & 25 & 1 & \\
\hline$<18.5$ & 6,169 & 20 & 96,092 & 20 & $0.80(0.27-2.35)$ & \\
\hline $23-24.9$ & 2,982 & 8 & 45,895 & 17 & $0.67(0.20-2.24)$ & \\
\hline $25-29.9$ & 4,418 & 17 & 66,762 & 25 & $0.98(0.33-2.93)$ & \\
\hline $30+$ & 1,023 & 1 & 15,165 & 6 & $0.26(0.03-2.29)$ & \\
\hline \multicolumn{6}{|l|}{ History of family cancer } & \multirow[t]{3}{*}{0.412} \\
\hline No & 13,503 & 44 & 201,454 & 21 & 1 & \\
\hline Yes & 4,781 & 22 & 79,603 & 27 & $1.24(0.74-2.08)$ & \\
\hline \multicolumn{6}{|l|}{ Smoking } & \multirow[t]{4}{*}{0.132} \\
\hline Non-smoker & 14,146 & 48 & 224,014 & 21 & 1 & \\
\hline Ex-smoker & 1,520 & 9 & 22,605 & 39 & $1.89(0.93-3.86)$ & \\
\hline Current-Smoker & 2,931 & 7 & 47,050 & 14 & $0.69(0.31-1.53)$ & \\
\hline \multicolumn{6}{|l|}{ Duration of smoking (years) } & \multirow[t]{5}{*}{0.553} \\
\hline Non-smoker & 14,140 & 48 & 223,943 & 21 & 1 & \\
\hline $1-10$ & 370 & 2 & 5,502 & 36 & $1.74(0.42-7.16)$ & \\
\hline $11-20$ & 714 & 1 & 12,066 & 8 & $0.38(0.05-2.78)$ & \\
\hline$>20$ & 3,362 & 13 & 52,018 & 24 & $1.17(0.63-2.16)$ & \\
\hline \multicolumn{7}{|l|}{ No. of cigarette / year } \\
\hline Non-smoker & 13,467 & 47 & 209,620 & 22 & 1 & \multirow[t]{3}{*}{0.119} \\
\hline Low $(1-5,776)$ & 1,857 & 5 & 34,063 & 14 & $0.59(0.23-1.53)$ & \\
\hline High $(5,776-62,051)$ & 1,508 & 9 & 22,203 & 40 & $1.83(0.9-3.74)$ & \\
\hline \multicolumn{6}{|l|}{ Alcohol drinking } & \multirow[t]{4}{*}{0.772} \\
\hline Non-drinker & 4,988 & 15 & 70,460 & 21 & 1 & \\
\hline Ex-drinker & 1,163 & 5 & 17,816 & 28 & $1.27(0.46-3.54)$ & \\
\hline Current-drinker & 2,817 & 10 & 49,738 & 20 & $0.85(0.37-1.95)$ & \\
\hline \multicolumn{6}{|l|}{ Duration of drinking (years) } & \multirow[t]{5}{*}{0.992} \\
\hline Non-drinker & 4,971 & 15 & 70,199 & 21 & 1 & \\
\hline $1-10$ & 967 & 4 & 16,886 & 23 & $1.02(0.33-3.12)$ & \\
\hline $11-20$ & 1,146 & 5 & 20,171 & 24 & $1.06(0.38-2.97)$ & \\
\hline$>20$ & 1,819 & 6 & 29,590 & 20 & $0.89(0.34-2.33)$ & \\
\hline \multicolumn{6}{|l|}{ Frequency of drinking } & \multirow{6}{*}{0.972} \\
\hline Non-drinker & 4,971 & 15 & 70,199 & 21 & 1 & \\
\hline Daily & 540 & 2 & 7,805 & 25 & $1.15(0.26-5.05)$ & \\
\hline Weekly & 1,209 & 5 & 18,143 & 27 & $1.24(0.45-3.45)$ & \\
\hline Monthly & 3,689 & 11 & 56,843 & 19 & $0.86(0.39-1.89)$ & \\
\hline$<1 /$ month & 2,587 & 8 & 38,118 & 20 & $0.96(0.40-2.29)$ & \\
\hline \multicolumn{6}{|l|}{ Unit of alcohol (grams/day) } & \multirow[t]{4}{*}{0.453} \\
\hline Non-drinker & 4,971 & 15 & 70,199 & 21 & 1 & \\
\hline$<50$ & 6,180 & 18 & 95,012 & 18 & $0.84(0.42-1.69)$ & \\
\hline$\geq 50$ & 1,837 & 8 & 25,796 & 31 & $1.46(0.62-3.47)$ & \\
\hline
\end{tabular}

Table 3. Multivariate Analysis of Potential Risk Factors

\begin{tabular}{|c|c|c|c|c|c|c|}
\hline Factors & Numbers & $\begin{array}{l}\text { Number } \\
\text { of CRC }\end{array}$ & $\begin{array}{l}\text { Person-time } \\
\text { (person-yesr) }\end{array}$ & $\begin{array}{c}\text { Crude HR } \\
(95 \% \mathrm{CI})\end{array}$ & $\begin{array}{c}\text { Adjusted HR } \\
(95 \% \mathrm{CI})\end{array}$ & p-value \\
\hline$\overline{\operatorname{Sex}}$ & & & & & & 0.187 \\
\hline Female & 13,489 & 13,489 & 13,489 & 1 & 1 & \\
\hline Male & 6,372 & 6,372 & 6,372 & $1.34(0.83-2.16)$ & $1.67(0.80-3.49)$ & \\
\hline History of family cancer & & & & & & 0.525 \\
\hline No & 13,503 & 44 & 201,454 & 1 & 1 & \\
\hline Yes & 4,781 & 22 & 79,603 & $1.24(0.74-2.08)$ & $0.96(0.85-1.09)$ & \\
\hline Working hours/day (hours) & & & & & & 0.490 \\
\hline 8 & 8,382 & 27 & 125,549 & 1 & 1 & \\
\hline$<8$ & 4,163 & 17 & 61,342 & $1.31(0.71-2.40)$ & $1.32(0.72-2.42)$ & \\
\hline$>8$ & 2,513 & 7 & 39,099 & $0.82(0.36-1.88)$ & $0.84(0.36-1.93)$ & \\
\hline Unemployed & 1,182 & 8 & 20,214 & $1.70(0.77-3.77)$ & $1.83(0.40-2.02)$ & \\
\hline Smoking & & & & & & 0.104 \\
\hline Non-smoker & 14,146 & 48 & 224,014 & 1 & 1 & \\
\hline Ex-smoker & 1,520 & 9 & 22,605 & $1.89(0.93-3.86)$ & $1.34(0.52-3.46)$ & \\
\hline Current-Smoker & 2,931 & 7 & 47,050 & $0.69(0.31-1.53)$ & $0.51(0.18-1.38)$ & \\
\hline Unit of alcohol (grams/day) & & & & & & 0.569 \\
\hline Non-drinker & 4,971 & 15 & 70,199 & 1 & 1 & \\
\hline$<50$ & 6,180 & 18 & 95,012 & $0.84(0.42-1.69)$ & $0.68(0.32-1.44)$ & \\
\hline$\geq 50$ & 1,837 & 8 & 25,796 & $1.46(0.62-3.47)$ & $1.08(0.43-2.71)$ & \\
\hline
\end{tabular}




\section{Results}

In total, a sample of 19,861 subjects with a total observation time of 310,611 person-years were observed which included 71 cases of histologically confirmed CRC. The general demographic characteristics of all cohort members are summarized in Table 1. Most participants were female, aged at least 41 years old at recruitment, never attended school or had only primary school level education, and were employed as farmers. The result of the univariate analysis are given in Table 2. The univariate analysis identified only age at recruitment as significantly associated with the risk of CRC, especially age more than 50 year old (HRage 51-60=3.03, 95\% CI, 1.26-7.29, and HRage $>60=4.29,95 \%$ CI, 1.68-10.98).

The results from the multivariable cox regression are shown in Table 3. None of the potential risk factors were significantly related to the risk of CRC. In our sample, we note that the survival experience was poorer among males, although sex could not be shown to be associated with CRC (HRsex $=1.67,95 \%$ CI, 0.80-3.49). In our sample those who were ex-smoker, and those who drink alcohol beverage more than 50 gram per day were more at risk, but again, this is cannot be inferred to the populations (HRex-smoker $=1.34,95 \%$ CI, 0.52-3.46, and HRalc $>50=1.08,95 \%$ CI, 0.43-2.71). Whereas, those who had a family history of cancer, those who working hour $>8$ hours per day, and those who were current-smoker, the survival experience appeared better, and these factors appeared to decrease risk of CRC. However, these could not be show to be significantly protective of CRC (HRfam-cancer=0 96 , 95\% CI, 0.85-1.09, HRworking hour $=0.84,95 \%$ CI, 0.361.93, and HRcurrent-smoker= $0.51,95 \%$ CI, 0.18-1.38).

\section{Discussion}

The objective of this cohort study was to determine the environmental risk factors for CRC in the Thai population. To the best of our knowledge, this is the first prospective cohort study of the association between environmental factors and CRC risk in the Thai population. Surprising our study did not find significant associations between any of the factors and the subsequent development of colorectal cancer.

In the present study, family history of cancer could not be shown to be increase CRC risk, and indeed our result indicate that it may be protective. This is consistent with a case-control study of the The $\mathrm{CpG}$ island methylator phenotype (CIMP) status of 3,119 primary populationbased colorectal cancer tumors from the multinational Colon Cancer Family Registry, reported that family history of CRC had decreased risk for CIMP, that represents a subset of colorectal cancer (Weisenberger et al., 2015). However, our result are in contrast with most previous studies which report family history of CRC to increase the risk for CRC (Johns and Houlston, 2001; Zhivotovskiy et al., 2012; Castiglione et al., 2012; Turati et al., 2013; Askling et al., 2001; Stegeman et al., 2013). Indeed, family history of any cancer has been shown to be associated with CRC in the Thai population (Sriamporn et al., 2007; Promthet et al., 2010; Poomphakwaen et al., 2014). Our inability to identify family history as a risk factor may stem from limited information from the case report form. Our study employed a question regarding family history of any type of cancer, not specifically CRC.

We found that alcohol consumption was not associated with CRC. Studies on the effect of alcohol on CRC are mixed. Some previous studies have shown that alcohol consumption is associated with CRC (Cho and Kim, 2011; Zhivotovskiy et al., 2012). A study of patients who underwent colonoscopic polypectomy of colorectal adenoma in Korea reported alcohol drinking was related to the development of advanced colorectal adenoma, especially in the patients with alcoholic liver diseases (Song et al., 2015). However, a meta-analysis investigating the association between alcohol intake and colorectal serrated polyp with the dose-response of alcohol intake indicates the light alcohol intake does not increase risk of colorectal serrated polyp (Wang et al., 2015). Also a case-control study in India (Ganesh et al., 2009), and a previous study in the Thai population found no association between alcohol consumption and CRC (Sriamporn et al., 2007; Poomphakwaen et al., 2014).

The present study did not show smoking to be associated with CRC. This is consistent with some other studies. For instance, no relationship between smoking and CRC was found in a US Prospective cohort study of white males (Hsing et al., 1998), Nor did previous studies in Japan (Nisa et al., 2010) or Holland (Tiemersma et al., 2002), or indeed, earlier colorectal case-control studies in Thailand (Promthet et al., 2010; Poomphakwaen et al., 2014). However, several colorectal cancer studies have shown a relationship between smoking and CRC development (Botteri et al., 2008; Phipps et al., 2011; Leufkens, et al., 2011; Gong et al., 2012; Zhivotovskiy et al., 2012; Peng et al., 2013; Stegeman et al., 2013).

Our study did have some limitations. First we had a small number of cases which may have impacted the power of our analysis. However, there was little indication that any of the effects were clinically risky, and failed to be identified only because of low power. On the contrary, we found most risk factors identified in other studies to have negligible risk and even to be marginally protective. Second, all environmental variables in our study came from a single interview of participants on entry into the KKCS. It is quite possible that many subject may have changed their habit after recruitment.

The present study is the first cohort study of CRC in Thailand and our study involved a large cohort. We found no association between life style, environmental factors and the risk of CRC development. We found little evidence to suggest smoking, and alcohol were risk factors for CRC. Further study is needed to investigate why environmental risk factors of CRC identified as important in other populations appear to have little impact on risk of CRC in Thais. The impact of dietary habit and gene polymorphism on CRC risk need further investigate in this population.

\section{Acknowledgements}

The authors would like to acknowledge the financial support of a Royal Golden Jubilee Ph.D. Program 
Scholarship for Mr.Kirati Poomphakwaen and Professor Supannee Promthet (Grant No.PHD/ 0102/ 2553) from the Thailand Research Fund, Khon Kaen University, and the National Research Council of Thailand. Thanks are due to all the staff at the Cancer Unit of Srinagarind Hospital, Faculty of Medicine, Khon Kaen University, for their kind help. We would like to acknowledge Professor Vanchai Vatanasapt and Dr. Maxwell Parkin for initiating the Khon Kaen Cohort Study. Finally, Thanks are due to Dr.Cameron Hurst for his advice and assistance in writing this paper.

\section{References}

Askling J, Dickman P, Kalen P, Brostrom O (2001). Family history as a risk factor for colorectal cancer in inflammatory bowel disease. Gastroenterol, 120, 1356-62.

Botteri E, Iodice S, Bagnardi V, et al (2008). Smoking and colorectal cancer: a meta-analysis. J Am Med Associat, 300, 2765-78.

Castiglione G, Visioli CB, Zappa M, et al (2012). Familial risk of colorectal cancer in subjects attending an organised screening programme. Dig Liver Dis, 44, 80-3.

Cho AY, Kim J (2011). Association between alcohol consumption and colorectal carcinogenesis: an ecological study in Korea. Asian Pac J Cancer Prev, 12, 761-4.

De Stefani E, Ronco AL, Boffetta P, et al (2012). Nutrientderived dietary patterns and risk of colorectal cancer: a factor analysis in Uruguay. Asian Pac J Cancer Prev, 13, 231-5.

Durko L, Malecka-Panas E (2014). Lifestyle Modifications and Colorectal Cancer. Curr Colorectal Cancer Rep, 10, 45-54.

Ferlay J, Soerjomataram I, Ervik M, et al (2013). GLOBOCAN 2012 v1.0, Cancer Incidence and Mortality Worldwide: IARC CancerBase No.11. International Agency for Research on Cancer. internet. Retrieved May 13, 2014, from http:// globocan.iarc.fr

Ganesh B, Talole SD, Dikshit R (2009). A case-control study on diet and colorectal cancer from Mumbai, India. Cancer Epidemiol, 33, 189-93.

Gong J, Hutter C, Baron JA, et al (2012). A pooled analysis of smoking and colorectal cancer: Timing of exposure and interactions with environmental factors. Cancer Epidemiol Biom Prev, 21, 1974-85.

Hsing AW, McLaughlin JK, Chow WH, et al (1998). Risk factors for colorectal cancer in a prospective study among U.S. white men. Int J Cancer, 77, 549-53.

Leufkens AM, Van Duijnhoven FJ, Siersema PD, et al (2011). Cigarette smoking and colorectal cancer risk in the European Prospective Investigation into Cancer and Nutrition study. Clin Gastroenterol Hepatol, 9, 137-44.

Johns L, Houlston R (2001). A systematic review and meta-analysis of familial colorectal cancer risk. AM J Gastroenterol, 96, 2993-3003

Nisa H, Kono S, Yin G, et al (2010). Cigarette smoking, genetic polymorphisms and colorectal cancer risk: the Fukuoka Colorectal Cancer Study. BMC Cancer, 10, 274.

Peng XE, Jiang, YY, Shi, XS, HuZJ (2013). NQO1 609C>T polymorphism interaction with tobacco smoking and alcohol drinking increases colorectal cancer risk in a Chinese population. Gene, 521, 105-10.

Phipps AI, Baron J, Newcomb PA (2011). Prediagnostic smoking history, alcohol consumption, and colorectal cancer survival: the Seattle Colon Cancer Family Registry. Cancer, 117, 4948-57.

Poomphakwaen K, Promthet S, Suwanrungruan K, et al (2014). XRCC1 gene polymorphism, diet and risk of colorectal cancer in Thailand. Asian Pac J Cancer Prev, 13, 4017-23.
Promthet S, Pientong C, Ekalaksananan T, et al (2012). Risk factors for rectal cancer and methylenetetrahydrofolate reductase polymorphisms in a population in Northeast Thailand. Asian Pac J Cancer Prev, 13, 4017-23.

Promthet SS, Pientong C, Ekalaksananan T, et al (2010). Risk factors for colon cancer in Northeastern Thailand: interaction of MTHFR codon 677 and 1298 genotypes with environmental factors. J Epidemiol, 20, 329-38.

Song YK,park YS, Seon CS, et al (2015). Alcohol drinking increased the risk of advanced colorectal adenomas. Intest Res, 13, 74-9.

Sriamporn S, Wiangnon S, Suwanrungruang K, et al (2007). Risk factors for colorectal cancer in northeast Thailand: lifestyle related. Asian Pac J Cancer Prev, 8, 573-7.

StataCorp. (2007). Stata Statistical Software: Release 10. College Station, TX: StataCorp LP.

Stegeman I, De Wijkerslooth TR, Stoop EM, et al (2013). Colorectal cancer risk factors in the detection of advanced adenoma and colorectal cancer. Cancer Epidemiol, 37, 278-83.

Sung JJ, Lau JY, Goh K L, Leung WK (2005). Asia Pacific Working Group on Colorectal Cancer Increasing incidence of colorectal cancer in Asia: implications for screening. Lancet Oncol, 6, 871-6.

Tiemersma EW, Kampman E, Bueno de Mesquita HB, et al (2002). Meat consumption, cigarette smoking, and genetic susceptibility in the etiology of colorectal cancer: results from a Dutch prospective study. Cancer Causes Control, 13, 383-93.

Turati F, Edefonti V, Bosetti C, et al (2013). Family history of cancer and the risk of cancer: A network of case-control studies. Ann Oncol, 24, 2651-6.

Wang J, Zhao Y, Jiang J, et al (2010). Polymorphisms in DNA repair genes $X R C C 1, X R C C 3$ and $X P D$, and colorectal cancer risk: A case-control study in an Indian population. J Cancer Res Clin Oncol, 136, 1517-25.

WangYM, Zhou QY, Zhu JZ, et al (2015). Systematic review with meta-analysis: Alcohol consumption and risk of colorectal serrated polyp. Dig Dis Sci, 60, 1889-902

Weisenberger DJ, Levine AJ, Long TI, et al (2015). Association of the colorectal CpGisland methylator phenotype with molecular features, risk factors, and family history. Cancer Epidemol Biomarker Prev, 24, 512-9.

Yee YK, Tan VP, Chan P, et al (2009). Epidemiology of colorectal cancer in Asia. J Gastroenterol Hepatol, 24, 1810-6.

Zhivotovskiy AS, Kutikhin AG, Azanov AZ, et al (2012). Colorectal cancer risk factors among the population of south-east siberia: A case-control study. Asian Pac J Cancer Prev, 13, 5183-8. 